\title{
Formação em Psicologia e oligopolização do ensino superior no Brasil
}

Joao Paulo Macedo. Universidade Federal do Piauí Brenda Brito Ramos. Universidade Federal do Piauí Carlivane de Jesus Souza. Universidade Federal do Piauí Marta Savana de Sousa Lima. Universidade Federal do Piauí Karyne Pamela B.C Fonseca. Universidade Federal do Piauí

\section{Resumo}

Objetiva-se situar o cenário atual da organização dos cursos de Psicologia no Brasil frente ao processo de expansão e mercantilização do ensino superior. Metodologicamente realizou-se pesquisa descritiva-exploratória com base nas informações oficiais da educação superior relacionadas aos cursos de Psicologia, além de relatórios financeiros dos grupos educacionais e consultorias especializadas em fundos de investimentos das IES que ofertam cursos de Psicologia. Os resultados indicam o aprofundamento do contexto de mercantilização do ensino superior e a formação de players da educação (grandes oligopólios), que concentram significativas parcelas do mercado. A formação em Psicologia segue a mesma tendência: intensificação do caráter privado e interiorização das agências formadoras, inclusive em localidades de menor porte populacional, além de um considerável percentual $(26,25 \%)$ de cursos vinculados a grandes grupos educacionais no Brasil.

Palavras-chave: ensino superior; interiorização de cursos de graduação; oligopólios da educação; formação do psicólogo.

\section{Abstract}

Training in psychology and the oligopolization of higher education in Brazil. This article aimed to describe the current scenario of organization of psychology courses in Brazil, considering the process of expansion and mercantilization of higher education. Methodologically, this study was of exploratory-descriptive design, based on official information related to higher education, and on financial reports of educational groups and specialized consultancies in investment funds. Results showed a deepening of the process of mercantilization of higher education and the formation of players in education (great oligopolies), which concentrate a significant share of the market. The training in psychology follows the same tendency: intensification of the private sector and interiorization of the institutions, including smaller regions, it was also observed that a significant percentage (26.25\%) of courses are linked with larger educational groups in Brazil.

Keywords: higher education; interiorization of undergraduate courses; oligopolies of education; training in psychology.

\section{Resumen}

Formación en psicología y oligopolización de la enseñanza superior en Brasil. El objetivo es situar el escenario actual de la organización de los cursos de psicología en Brasil, a través del proceso de expansión y mercantilización de la enseñanza superior. Metodológicamente se llevó a cabo una investigación descriptiva y exploratoria basada en las informaciones oficiales de la educación superior, además de informes financieros de los grupos educacionales y consultores especializados en fondos de inversión. Los resultados indican la profundización del contexto de mercantilización de la enseñanza superior y la formación de players de la educación (grandes oligopolios), que concentran importantes cuotas del mercado. La formación en psicología sigue la misma tendencia: la intensificación del carácter privado y la interiorización de las agencias de formación, incluso en los pueblos más pequeños, además del importante porcentaje $(26,25 \%)$ de cursos vinculados a los grandes grupos educacionales en Brasil. Palabras clave: enseñanza superior; interiorización de los cursos de graduacion; oligopolios de la educación; formación del psicólogo. 
O enfoque deste artigo é a formação em Psicologia no contexto da mercantilização do ensino superior e de formação de grupos educacionais que concentram significativas fatias do mercado nacional. Sob o peso dos ditames das agências internacionais multilaterais a educação foi alçada como mercadoria negociável, resultando no crescimento vertiginoso do mercado privado formando inclusive grandes monopólios por meio de fusões e aquisições de instituições de ensino superior (IES) (Gaspar \& Fernandes, 2014). Para compreender este cenário, tomamos as mudanças ocorridas no contexto de crise e rearranjo global do capitalismo em meio ao processo de acumulação flexível e das políticas de ajuste estatal de base neoliberal. Tais processos, como atesta Netto (2004), são inerentes à mundialização operada pelo capitalismo, sobretudo, o financeiro, e que tem acarretado, no caso da educação, sucessivas transformações no ensino superior em nosso país.

O solo para abrir o caminho para tornar a educação superior um bem de consumo no Brasil remonta o período da ditadura civil-militar, notadamente a Reforma Universitária de 1968. Proposta para responder à crise na educação e insatisfações relacionadas à restrição ao acesso (elitismo), além do engessamento da organização e estrutura universitária (Martins, 2009), a Reforma impulsionou a modernização das universidades públicas e a ampliação da presença do setor privado na educação superior (Carvalho, 2013). Foi assim que se estabeleceu um novo tipo de ensino privado no país: "estruturado nos moldes de empresas educacionais voltadas para a obtenção de lucro econômico e para o rápido atendimento de demandas do mercado educacional" (Martins, 2009, p. 17).

Como exemplo, em 1968, do total de 278.295 matrículas o setor privado detinha $44,7 \%$. Dois anos depois o percentual chegou a 50,5\%, seguindo com níveis cada vez mais expressivos de crescimento até alcançar 63,3\% em 1980 (Sampaio, 1991). Ficou patente, deste modo, a ascensão das instituições privadas com perfil marcadamente empresarial no Brasil, considerando que antes da Reforma de 1968 o setor privado era dominado por instituições confessionais e comunitárias que funcionavam sob os mesmos moldes das públicas.

Com a Constituição de 1988, ao garantir o princípio da autonomia universitária, o setor privado logo tratou de transformar certas IES em universidades, pois passariam a contar com a vantagem de ofertar cursos mais diversificados ao sabor do mercado. Como resultado, entre 1985 e 1996, triplicou o número de universidades particulares passando de 20 para 64 (Martins 2009).
Aprofundar a ideia da educação como mercadoria, consolidando-a como bem de consumo, foi uma das estratégias no bojo de um conjunto mais amplo de ajustes e reconversões, que o capitalismo em sua era monopolista encontrou para dar um novo dinamismo e salto frente à crise de acumulação do capital resultante do esgotamento do padrão de crescimento fordista-keynesiano, em 1970 (Antunes, 1999). A resposta à crise veio com um amplo processo de restruturação produtiva e introdução de novas tecnologias, base objetiva da precarização do trabalho e intensificação e ampliação da exploração da classe trabalhadora. O resultado foi a flexibilização e diversificação das formas de contratação, salários e direitos, além da desmobilização e desmonte das formas de organização e resistência da classe trabalhadora, com o controle da subjetividade dos trabalhadores (Alves, 2009). Tais aspectos provocaram impactos não apenas econômicos, mas, sobretudo, político e cultural com mudanças na correlação de forças entre capital e trabalho.

O Estado passa a ter um papel importante nessa empreitada, pois funcional ao capitalismo monopolista (Netto, 2004) garante condições necessárias à acumulação, por meio de contrarreformas baseadas na ofensiva neoliberal. No Brasil, tal ofensiva apresenta-se com maior intensidade na década de 1990 no Governo Fernando Collor de Melo (1990-1992), sendo aprofundada no Governo Fernando Henrique Cardoso (1995-2002). No caso do primeiro, as contrarreformas ocorreram na tentativa de reverter o grave quadro inflacionário herdado dos anos 1980; no segundo, a busca pela estabilidade da economia resultou na Reforma do Estado, no tocante a sua função e estrutura, tornando-o mais eficiente e gerencial com a redução da participação do setor público na garantia e efetivação de direitos, consequentemente, com o fortalecimento do mercado ao transformar direitos em mercadoria (Oliveira, 2011).

É nesse bojo que o preceito de transformar a educação em mercadoria no Brasil é aprofundado, adotando os princípios das agendas dos organismos internacionais (Banco Mundial e Organização Mundial do Comércio/ $\mathrm{OMC}$ ), para adequar a educação ao novo modelo de acumulação flexível, cuja centralidade foi a desregulamentação do ensino superior e a retração de gastos públicos, acarretando o fortalecimento e a ampliação do setor privado em detrimento e estagnação do público (Martins, 2009). A própria Lei de Diretrizes e Bases da Educação Nacional (LDB), aprovada em 1996, ano seguinte ao Brasil tornar-se país-membro da OMC, representou um marco desse processo ao tornar a educação livre à iniciativa 
privada; e, no caso do ensino superior, ao reconhecer a existência e o funcionamento de instituições empresariais com fins lucrativos, inclusive com atuação de forma isolada e voltada para o mercado (Chaves, 2010).

Os resultados foram logo percebidos. Enquanto em 1991, 75,1\% das IES estavam concentradas no setor privado e $24,9 \%$ no setor público, em 2002 o percentual da rede privada subiu para $88,1 \%$ e o da pública caiu drasticamente para $11,9 \%$. Por outro lado, esse vertiginoso crescimento começou a apresentar sinais de retração com um grande número de vagas ociosas, devido à queda na taxa de ocupação das IES privadas, que passou de 78,7\% em 1999 para 62,6\% em 2002 (Corbucci, 2004).

A mudança de rumos na esfera federal, com o início do ciclo do Governo Luís Inácio Lula da Silva (2003-2010), continuado no Governo Dilma Rousseff na presidência do Brasil (2011-2016), trouxe um novo alento para o setor, devido à reorganização do bloco de poder em torno do Partido dos Trabalhadores. Assim, em meio a um amplo conjunto de ações em diversos setores, levou-se a cabo a reorientação das políticas educacionais, incluindo o ensino superior, atendendo, como bem expressou Marques e Mendes (2007), a dois senhores: de um lado, às camadas populares e os movimentos sociais, a exemplo das demandas por ampliação, democratização do acesso e apoio permanência aos estudantes; do outro, ao grande capital financeiro, ávido por novos mercados e lucratividade.

Os programas e ações propostos nesse período para o aumento do acesso ao ensino superior foram: a) Programa de Apoio a Planos de Reestruturação e Expansão das Universidades Federais (Reuni); b) Plano Nacional de Assistência Estudantil (PNAES), com o apoio a permanência de estudantes de baixa renda nas IFES; c) Programa Universidade para Todos (ProUni) com a concessão de bolsas de estudos integrais e parciais em IES privadas para cursos de graduação e sequenciais de formação específica; d) Sistema de Ensino a Distância (EaD), iniciado em 1998 no Governo Fernando Henrique Cardoso e massificado a partir de 2005, no Governo Luís Inácio Lula da Silva, com o crescente número de IES privadas credenciadas para essa modalidade de ensino, acompanhado da criação da Universidade Aberta (UAB); e) Programa Nacional de Acesso ao Ensino Técnico e Emprego (Pronatec), que dinamizou o processo de expansão e interiorização da Rede Federal de Educação Profissional, Científica e Tecnológica (Institutos Federais) e a criação da Rede E-Tec para oferta de cursos na modalidade EaD no setor público e privado; e f) a continuidade do Fundo de Financiamento Estudantil (Fies), criado em
1999 no Governo Fernando Henrique Cardoso, reformatado e ampliado em 2010 no Governo Luís Inácio Lula da Silva, chegando ao seu ápice no Governo Dilma Rousseff.

Tal feito acabou beneficiando de forma desigual os setores público e privado. Mesmo com o salto de 45 para 63 universidades federais (ampliação de 40\%) e o aumento de 148 para 321 campi/unidades, a hegemonia de IES no setor privado não parou de crescer. Do total de 2.368 instituições registradas no censo da educação superior em 2014, 87,41\% pertenciam ao setor privado. Quanto ao número de cursos, do total de 32.878 ofertados em 2014 com grau acadêmico do tipo bacharelado, licenciatura e tecnológico, 33,54\% foram no setor público e $66,43 \%$ no privado. Outro aspecto a ser considerado é que das 7.828.013 matrículas efetuadas em 2014, 82,85\% foi na modalidade presencial e $17,15 \%$ a distância, dado que sinaliza o peso que ganhou os cursos EaD no país, bastante visados pelo setor privado (Ministério da Educação, 2015a). São dados que indicam a força da expansão do ensino superior no Brasil, abrindo, sobretudo, margem para novas investidas do mercado, considerando que a "taxa de conclusão do ensino médio passou de 45,5\% para 60,8\% entre 2004 e 2014" (IBGE, 2015, p. 50).

O quadro de desregulamentação da legislação e flexibilização do setor para o capital financeiro, acompanhado ainda do papel do Estado atuando na transferência do fundo público (desonerações tributárias, isenções, financiamentos diretos, redução de encargos trabalhistas, compra de vagas), além da participação do Banco Nacional de Desenvolvimento Econômico e Social (BNDES) com a criação de linhas de financiamento a juros baixos para as IES, fortaleceu ainda mais a participação do setor privado no ensino superior brasileiro nos últimos anos. Tanto que fez com que o setor assumisse novos contornos com a disputa do fundo público pelo grande capital, resultando na tendência à oligopolização, por meio de fusões e aquisições de IES, ou seja, com a formação de grupos econômicos (Mancebo, 2015).

Para Tavares (2014), trata-se de um novo ciclo, que se diferencia dos períodos anteriores em que a maioria das IES figuravam apenas como "instituições privado-mercantis, geridas por entidades mantedoras que se tratavam de organizações empresariais de natureza familiar" (p. 92). Como exemplo, em 2002, as 10 maiores IES em número de matrículas representavam $12,96 \%$ de todo o sistema de ensino superior do país, enquanto que em 2013 esse índice passou para $29,07 \%$, sendo que as nove primeiras posições foram ocupadas por grupos educacionais nacionais oligopolizados (Tabela 1). 
Tabela 1. Instituições e Grupos Educacionais com Maior Número de Matrículas nos Anos 2002 e 2003.

\begin{tabular}{|c|c|c|c|c|c|c|c|}
\hline \multicolumn{4}{|c|}{2002} & \multicolumn{4}{|c|}{2013} \\
\hline & IES & $\begin{array}{c}\text { Categoria } \\
\text { Administrativa }\end{array}$ & Matrículas & & IES & $\begin{array}{c}\text { Categoria } \\
\text { Administrativa }\end{array}$ & Matrículas \\
\hline 2 & ESTÁCIO & Privada & 85.693 & 2 & ANHANGUERA & Privada & 442.000 \\
\hline 3 & USP & Estadual & 42.871 & 3 & ESTÁCIO & Privada & 315.700 \\
\hline 6 & PUC-MINAS & Privada & 34.078 & 6 & UNINOVE & Privada & 170.000 \\
\hline 7 & UNISINOS & Privada & 31.670 & 7 & UNICSUL & Privada & 55.000 \\
\hline 8 & UEG & Estadual & 31.575 & 8 & ÂNIMA EDUCAÇÃO & Privada & 49.000 \\
\hline 9 & UESPI & Estadual & 30.644 & 9 & SER EDUCACIONAL & Privada & 98.800 \\
\hline
\end{tabular}

* Anhanguera Educacional desde 2011.

** A KROTON não havia se fundido com a Anhanguera.

Fonte: Censo da Educação Superior (Ministério da Educação, 2002, 2015b).

Frente a esse cenário de expansão e financeirização do ensino superior no Brasil, somado ao fato de que historicamente os cursos de Psicologia são ofertados hegemonicamente pelo setor privado, ${ }^{1}$ buscamos refletir como a formação graduada em Psicologia se localiza nesse processo. Objetivamos, por este aspecto, (a) situar o cenário atual da organização dos cursos de Psicologia no Brasil em meio ao processo de expansão do ensino superior; (b) localizar as graduações em Psicologia pertencentes a grupos educacionais financeiros, considerando o processo de oligopolização em curso; e (c) analisar as principais tendências quanto a natureza dos cursos de Psicologia ofertados por esses grupos no país.

\section{Método}

Trata-se de uma pesquisa descritiva-exploratória a partir das informações oficiais e da base de dados dos censos da educação superior. Primeiramente filtramos as informações das respetivas bases de dados dos cursos de Psicologia no Brasil, com destaque para o ano de 2014 (sem excluir os anos anteriores). Inclui-se nessa busca também os dados oficiais da Plataforma E-mec de instituições e cursos de educação superior, com os quais centramos nas informações do tipo: localização, capital/interior, porte do município, tipo de IES, categoria administrativa, mantenedora, ano de criação e indicadores de qualidade (IGC, CC e ENADE). Ademais também buscamos os relatórios financeiros e de gestão dos grupos educacionais brasileiros e empresas de consultoria especializadas em fundos de investimentos, que têm operado no setor educacional no país e no mundo, disponíveis em domínio público. Quanto aos dados coletados dos censos da educação superior e do E-mec estes foram analisados com base na distribuição de frequências, traçando um perfil atualizado sobre a formação em Psicologia, com base nas variáveis anteriormente referidas e articulando com a literatura especializada que trata sobre o tema. A seguir, discorreremos sobre o panorama da formação em Psicologia no Brasil e o mercado dos grupos educacionais do ensino superior que contam com graduações em Psicologia.

\section{Resultados}

\section{Panorama da Formação em Psicologia no Brasil}

De acordo com o censo da educação superior de 2014 (Ministério da Educação, 2015a), contabiliza-se 562 cursos de Psicologia no país, sendo 549 ativos e 13 em extinção (sete em universidades federais, um em universidade estadual, um em faculdade municipal e quatro em instituições privadas). Chama atenção o número de cursos em extinção $(n=9)$ em universidades, especialmente no setor das públicas. Dos cursos em atividade, 84 funcionam em IES públicas (14,92\%), distribuídas em federais $(n=58)$, estaduais $(n=22)$ e municipais $(n=4), 438$ no setor privado $(77,79 \%)$ e 27 como IES $(4,79 \%)$ que foram criadas por leis estaduais ou municipais (até 1988), mas não mantidas completamente com recursos públicos (não gratuitas). No setor privado, a maioria dos cursos é ofertada em faculdades isoladas $(n=209)$, seguido das universidades $(n=155)$ e centros universitários $(n=74)$. Quanto ao 
número de matrículas, totalizam 207.070, o que equivale a $2,64 \%$ do total de matrículas do ensino superior brasileiro. Isso coloca a Psicologia na $7^{a}$ posição entre os cursos com maior número de matrículas. Cabe uma observação, os 10 primeiros cursos sob esta condição detêm $50 \%$ do que é ofertado no sistema de ensino superior do país. Quanto aos concludentes, identificamos 20.663 em 2014, sendo $19,53 \%$ no setor público e $80,46 \%$ no privado, dado que coloca novamente a Psicologia entre os 10 cursos do país com maior número de alunos concludentes ( $9^{a}$ posição). Os cursos de Psicologia pesquisados ofereceram, em 2014, 85.580 vagas $(7,94 \%$ nas públicas e $92,05 \%$ nas privadas) para o ingresso em processos seletivos. A procura por candidatos inscritos nos processos seletivos alcançou 350.193 candidatos (46,82\% no público e 53,17\% privado). Número que reafirma a Psicologia entre os 10 cursos com maior número de candidatos inscritos, perdendo apenas para Administração, Medicina, Direito, Pedagogia, Engenharia Civil, Ciências Contábeis e Enfermagem, respectivamente. Os cursos de graduação em Psicologia contaram, no respectivo ano, com somente $5,6 \%$ de vagas ociosas, registrando ainda baixa de $14,25 \%$ e $15,15 \%$ de matrículas trancadas e canceladas. Trata-se, portanto, de um quadro que reforça aquele apresentado por Bastos, Gondim e Rodrigues (2010), ao relatar que no período de 15 anos, mais precisamente entre 1991 a 2006, os percentuais quanto ao número de cursos, vagas oferecidas, demanda no vestibular, número de ingressos e concludentes cresceu acima de $100 \%$.

Sobre a distribuição dos cursos pelo país, observa-se como o processo de expansão do ensino superior no Brasil redimensionou a formação em Psicologia ao longo desses anos. Se recuperarmos as informações de 1985, no estudo "Quem é o psicólogo brasileiro?", em relação a formação acadêmica (Gomide, 1988), havia 81 cursos distribuídos em somente 17 estados da federação, com o destaque para a região Sudeste $(n=45)$, Sul $(n=15)$, Nordeste $(n=14)$, Centro Oeste $(n=5)$ e Norte $(n=2)$. São Paulo era responsável por $40 \%$ das vagas em Psicologia da época. Em 1995 o número de cursos saltou para 149, distribuídos no Sudeste $(n=81)$, Sul $(n=32)$, Nordeste $(n=22)$, Centro Oeste $(n=9) \mathrm{e}$ Norte $(n=5)$, com o destaque de 75 cursos nas capitais e 74 no interior (Brasil, 1995). Já no primeiro ano do Governo Luís Inácio Lula da Silva (2003), contávamos com 238 cursos de Psicologia, concentrados no Sudeste $(n=129)$, Sul $(n=54)$, Nordeste $(n=31)$, Centro Oeste $(n=16)$ e Norte $(n=8)$, com o destaque de 101 cursos nas capitais e 137 no interior.

Percebe-se, portanto, que com os programas e ações que reorientaram as políticas de ensino superior nos Governos Lula-Dilma, resultou tanto na expansão dos cursos de Psicologia pelo país, pois no período 2003-2014 houve crescimento de quase o dobro de cursos $(n=311)$ se comparado ao período de 1985-2003 ( $n=157)$, quanto aprofundou o deslocamento da formação de psicólogos dos grandes centros urbanos e capitais $(n=195,35,5 \%)$ para localidades do interior $(n=354,64,5 \%$ ) (Ministério da Educação, 2015a).

Sobre o processo de interiorização em curso, dos 354 cursos em funcionamento nos municípios do interior, 53 são ofertados em IES públicas, sendo $33 \mathrm{em}$ instituições federais, 15 nas estaduais e cinco nas municipais, e 311 nas privadas. Percebe-se, pela Figura 1, sucessivos picos de crescimento dos cursos em localidades do interior, a partir de 1997, se comparado nas capitais.

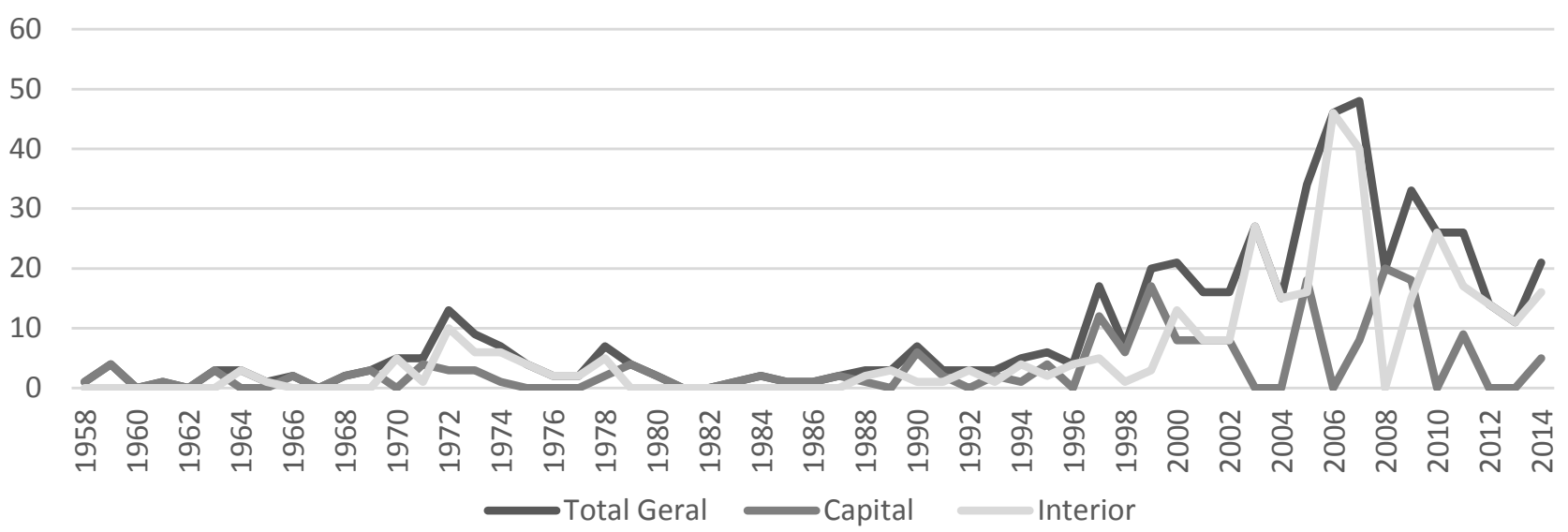

Figura 1. Série Histórica do Ano de Funcionamento dos Cursos de Psicologia no Brasil.

Fonte: Censo Da Educação Superior (Ministério da Educação, 2015a). 
Quanto ao porte dos municípios dos cursos ofertados no interior, contabiliza-se 39 em localidades de pequeno porte (até 49.999 hab.), 70 em médio pequeno porte (50 mil a 99.999 hab.), 140 em médio porte (100 mil a 299.999 hab.), 52 em médio grande porte (300 mil a 499.999 hab.) e 53 em grande porte (maior que 500 mil hab.). O destaque, conforme pode ser observado pela Figura 2, é para as cidades médias, especialmente aquelas voltadas para o setor produtivo nos mais diversos segmentos (agronegócio, indústria pecuária, indústria de base, automotiva, química e de gêneros alimentícios), bem como o setor de serviços (Macedo \& Dimenstein, 2011).

Por fim, observou-se que $59,8 \%$ dos cursos localizados em municípios do interior situam-se em regiões polos de desenvolvimento, considerando que o setor da educação superior constitui um importante agente de desenvolvimento local e regional, com a oferta de mão de obra especializada, e em alguns casos, especialmente na realidade das universidades públicas que contam com maior tradição e vocação para realização de ações de pesquisa e extensão universitária, com transferência de tecnologia às empresas e ao setor de serviços (Elias, 2007). Como exemplo, recorremos aos trabalhos de Rocha, Albuquerque e Marcelino (2008), Mello e Callou (2010) e Landini (2015), dentre outros, com estudos e pesquisas envolvendo ações de avaliação de políticas públicas, como também de compartilhamento de conhecimento e ferramentas interventivas (tecnologia social) junto a projetos sociais e de extensão rural.

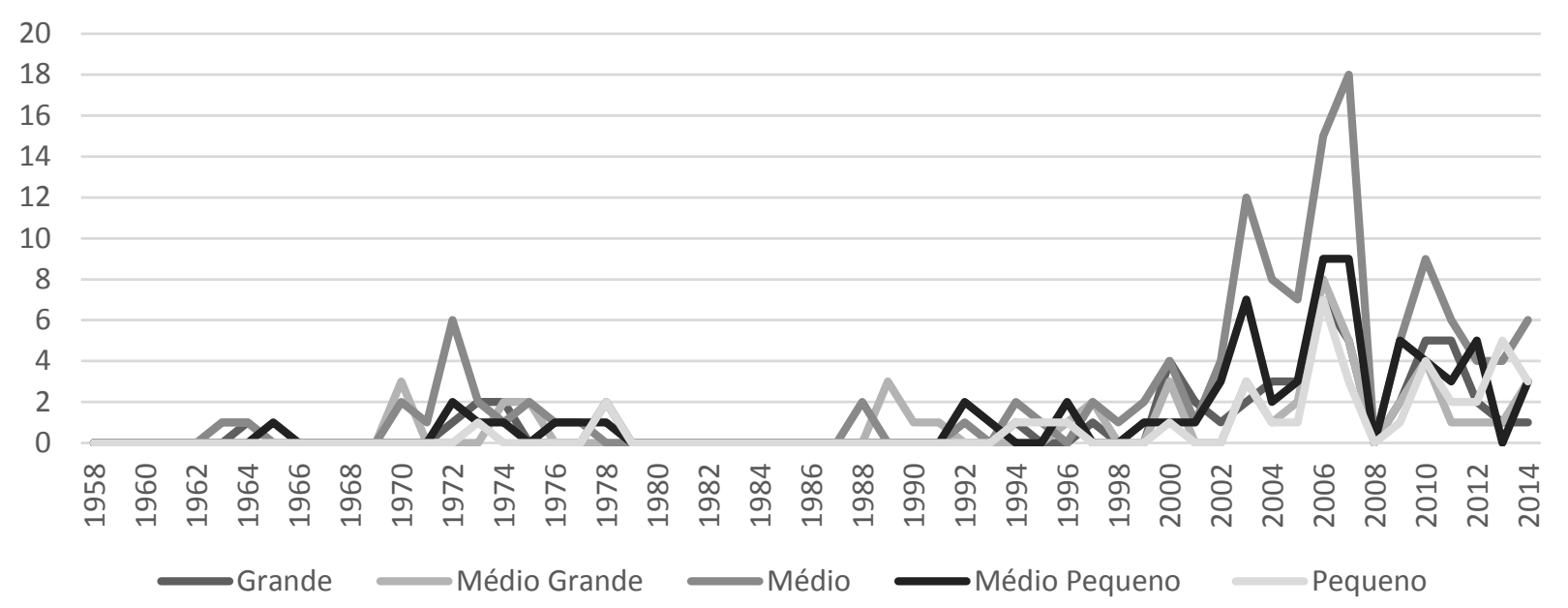

Figura 2. Série Histórica do Ano de Funcionamento dos Cursos de Psicologia por Porte dos Municípios em Localidades do Interior do Brasil. Fonte: Censo Da Educação Superior (Ministério da Educação, 2015a).

Em tese, tal panorama pode trazer uma maior diversificação quanto ao perfil de estudantes que têm ingressado nos cursos de Psicologia no Brasil (Yamamoto, Falcão, \& Seixas, 2011), além de aproximar a formação de realidades que podem apresentar novos cenários de práticas, reflexões, teorizações, objetos de pesquisa e de intervenção profissional. Porém, cabe ressaltar que a expansão do ensino superior com base no aprofundamento do setor educacional privado, em que para grande maioria dos casos o foco não é a qualidade da oferta dos cursos, pode apresentar entraves ao aparente caráter "inovador" desse processo.

\section{O Mercado dos Grupos Educacionais do Ensino Su- perior no Brasil que Ofertam Cursos de Psicologia}

A constituição das instituições de ensino superior em nosso país, quer seja de natureza pública ou privada, efetiva-se por um sistema composto por dois subsistemas: como mantenedora e como mantida. A mantenedora conta com personalidade jurídica e é responsável pela estrutura de ordem de propriedade (aspectos administrativos, financeiros, jurídicos, contábeis, pedagógicos, estrutura física e de manutenção, dentre outros), enquanto que a mantida é responsável por questões eminentemente acadêmicas e de prestação de serviços educacionais (ensino, pesquisa e extensão no âmbito da graduação e pós-graduação) (Silva Jr. et al., 2014).

As entidades mantenedoras, conforme expresso na LDB/96, podem ser de caráter público ou privado. No caso de serem privadas, classificam-se como fundações, associações civis ou sociedades civis de direito privado, ou, simplesmente, como empresas privadas. A abertura dada pela LDB provocou 
transformações na reestruturação das entidades mantenedoras privadas. Passaram a ser alvo tanto de investimento de ações de gerenciamento administrativo, financeiro e acadêmico para "buscar o lucro e o aumento e estabilidade patrimoniais" (Sguissardi, 2000 , p. 16), quanto de incentivo para assumirem uma "nova configuração com a formação de oligopólios, a partir da compra e venda de instituições e da abertura do capital na bolsa de valores" (Santos, Guimarães-losif, \& Chaves, 2013, p. 6).

As ações de compra e venda de instituições, especialmente de "porte médio ou pequeno em dificuldades financeiras, seja por meio de fusões de capital, cuja cooperação permite ganhos de escala e maior fatia de mercado, bem como novos nichos de mercado geográficos", inclusive com a formação de "conglomerados educacionais, em que a mantenedora empresa holding controla os negócios das demais", tem sido a tônica desse processo no Brasil (Carvalho, 2013, p. 769).

No levantamento realizado na Plataforma E-mec frente aos 438 cursos de Psicologia ofertados em instituições privadas no Brasil, pôde-se identificar que uma mesma entidade mantenedora é responsável por diferentes IES privadas, inclusive com localização em diversos estados da federação. Foi assim que identificamos 16 mantenedoras no domínio de pelo menos 115 cursos privados de Psicologia $(26,25 \%)$ vinculados a 49 IES. Tal dado evidencia o cenário de oligopolização da educação superior no Brasil no âmbito da formação em Psicologia em termos da concentração de cursos e IES na mão de poucos. Ademais, são cursos que seguem na lógica da interiorização da formação, pois 41 funcionam nas capitais e 74 no interior, assim distribuídos: Sudeste $(n=44)$, Sul $(n=36)$, Nordeste $(n=18)$, Centro Oeste $(n=9)$ e Norte $(n=8)$. Sobre os cursos do interior, 14 estão localizados em município de grande porte, 13 em médio grande, 21 em médio porte, 14 em médio pequeno e 12 em pequeno porte.

Na Tabela 2 podemos acompanhar de forma mais específica as mantenedoras que mais se destacaram, até o momento, na oferta dos cursos de Psicologia. Em síntese, os grandes players que atuam com oferta de cursos de Psicologia são a Estácio de Sá e a Anhanguera, sendo que esta última se fundiu com a Kroton Educacional, maior grupo educacional do mundo. Ambas estão presentes em todos os estados brasileiros. A Rede Pitágoras, o embrião da Kroton Educacional, detém muitas IES com unidades distribuídas pelo território nacional. Além desses grupos de maior destaque, outros também foram abertos para o grande capital, com investimento na bolsa de valores, são eles: Cruzeiro do Sul, Athenas Grupo Educacional, UNIASSELV Educacional, e Ser Educacional. Juntos, os sete grupos nacionais somam o total de 157 IES, dos quais apenas 36 instituições $(22,92 \%)$ são responsáveis por 64 cursos de Psicologia (14,61\%) em funcionamento no país. Ao todo, os 64 cursos ofertam cerca de 10.220 vagas nos processos seletivos dos cursos de Psicologia. Ademais, são 27 cursos localizados nas capitais e 38 em municípios do interior. No interior são 11 cursos em funcionamento em localidades de grande porte, $10 \mathrm{em}$ médio grande porte, 14 em médio porte, um em médio pequeno e um em pequeno porte.

Tabela 2. Principais Grupos Educacionais com Cursos de Psicologia.

\begin{tabular}{|c|c|c|c|c|}
\hline Grupo & IES & $\begin{array}{l}\text { Cursos de } \\
\text { Psicologia }\end{array}$ & Capital & Interior \\
\hline Estácio de Sá & 43 & 19 & 12 & $\begin{array}{l}4 \text { - Médio Porte } \\
2 \text { - Médio Grande Porte } \\
1 \text { - Grande Porte }\end{array}$ \\
\hline Anhanguera* & 61 & 15 & 2 & $\begin{array}{l}7 \text { - Grande Porte } \\
1 \text { - Médio Pequeno Porte } \\
2 \text { - Médio Grande Porte } \\
3 \text { - Médio Porte }\end{array}$ \\
\hline $\begin{array}{c}\text { Rede } \\
\text { Pitágoras* }\end{array}$ & 28 & 13 & 3 & $\begin{array}{l}2 \text { - Médio Grande Porte } \\
3 \text { - Grande Porte } \\
5 \text { - Médio Porte }\end{array}$ \\
\hline Ser Educacional & 7 & 8 & 6 & $\begin{array}{l}1 \text { - Médio Porte } \\
1 \text { - Médio Grande Porte }\end{array}$ \\
\hline $\begin{array}{l}\text { Cruzeiro do Sul } \\
\text { Educacional }\end{array}$ & 7 & 6 & 4 & 2 - Médio Grande Porte \\
\hline UNIASSELV & 6 & 2 & - & $\begin{array}{l}\text { 1- Médio Grande Porte } \\
\text { 1- Pequeno Porte }\end{array}$ \\
\hline $\begin{array}{l}\text { Athenas G. } \\
\text { Educacional }\end{array}$ & 5 & 1 & - & 1 - Médio Porte \\
\hline Total & 157 & 64 & 27 & 37 \\
\hline
\end{tabular}

*Marcas do Grupo Kroton.

Na Tabela 3 é possível acompanhar os indicadores quanto ao Índice Geral de Cursos (IGC), Conceito do Curso (CC) e do Exame Nacional de Desempenho de Estudantes (ENADE). A avaliação de instituições educativas é bastante recente no Brasil, como reporta Bastos, Gondim, Souza e Souza (2011). No caso do ensino superior, começa a ser discutido em 1980 com o Programa de Avaliação da Reforma Universitária e o Programa de Avaliação Institucional das Universidades Brasileiras (PAIUB), porém foi concretizado em 1995 com a Lei $n^{\circ}$ 9.131/95, que estabeleceu o Exame Nacional de Curso (Provão), acompanhado 
da Avaliação das Condições de Ensino e o Censo de Educação Superior. Em 2003, o Ministério da Educação reformatou as ações de avaliação do setor com a proposta do Sistema Nacional de Avaliação da Educação Superior (SINAES), aprovado pela Lei $\mathrm{n}^{\circ}$ 10.861/04 (Verhine \& Dantas, 2009).

Tabela 3. Principais Grupos Educacionais com Cursos de Psicologia.

\begin{tabular}{|c|c|c|c|c|c|c|}
\hline \multirow{2}{*}{ Grupo } & \multirow{2}{*}{ IES } & \multirow{2}{*}{$\begin{array}{l}\text { IES com Cursos de } \\
\text { Psicologia }\end{array}$} & \multirow{2}{*}{ Cursos de Psicologia } & \multicolumn{3}{|c|}{ Indicadores dos Cursos } \\
\hline & & & & IGC & CC & ENADE \\
\hline Estácio de Sá & 43 & 11 & 19 & Nota $3=11$ & $\begin{array}{c}\text { Nota } 3=8 \\
\text { Nota } 4=4 \\
\text { Nota } 5=1 \\
\text { SC }=6\end{array}$ & $\begin{array}{c}\text { Nota } 2=2 \\
\text { Nota } 3=7 \\
\text { Nota } 4=2 \\
\text { SC }=8\end{array}$ \\
\hline Rede Pitágoras* & 28 & 4 & 13 & $\begin{array}{l}\text { Nota } 3=7 \\
\text { Nota } 4=6\end{array}$ & $\begin{array}{c}\text { Nota } 3=3 \\
\text { Nota } 4=8 \\
S C=2\end{array}$ & $\begin{array}{c}\text { Nota } 3=7 \\
\text { Nota } 4=1 \\
S C=5\end{array}$ \\
\hline Ser Educacional & 7 & 3 & 8 & $\begin{array}{c}\text { Nota } 3=6 \\
\mathrm{SC}=2\end{array}$ & $\begin{array}{l}\text { Nota } 3=2 \\
\text { Nota } 4=4 \\
\text { Nota } 5=2\end{array}$ & $\begin{array}{c}\text { Nota } 3=1 \\
\mathrm{SC}=7\end{array}$ \\
\hline UNIASSELV & 6 & 2 & 2 & Nota $3=2$ & $\begin{array}{l}\text { Nota }=3 \\
\text { Nota } a=4\end{array}$ & $\begin{array}{l}\text { Nota } 3=1 \\
\text { Nota } 3=1\end{array}$ \\
\hline Athenas G. Educacional & 5 & 1 & 1 & Nota $3=1$ & Nota $=3$ & $\mathrm{SC}=1$ \\
\hline Total & 157 & 36 & 64 & & & \\
\hline
\end{tabular}

${ }^{*}$ Marcas do Grupo Kroton.

De acordo com Bittencourt, Casartelli e Rodrigues (2009), com o SINAES o número de conceitos adotados e divulgados pelo MEC na avaliação da educação superior no Brasil aumentou de um para quatro. Em 2004, a avaliação baseou-se somente no ENADE, derivado do desempenho de alunos ingressantes e concludentes nas provas. Em 2005 foi incorporado o Índice de Diferença de Desempenho (IDD) e em 2007 foi a vez do Conceito Preliminar de Curso (CPC), que sintetiza os resultados do ENADE e IDD num único valor. Em 2008, um novo índice foi criado, trata-se do IGC, que avalia a qualidade das instituições.

O IGC inaugura uma nova etapa nas avaliações em larga escala das IES, sendo divulgado pela grande imprensa anualmente. Os autores avaliam que "a grande repercussão da divulgação do IGC pela imprensa transformou este indicador num poderoso e polêmico instrumento de marketing institucional e de formação de opinião pública" (Bittencourt et al., 2009, p. 670). Em suma, para Rothen e Barreyro (2011), a criação dos índices CPC e IGC acabaram deslocando o SINAES para um mero sistema de regulação, ou seja, de supervisão da prestação de serviços educacionais, por meio de índices comparativos entre instituições, promovendo ranqueamentos, inserindo a educação na lógica de competição de mercado.

O mercado de fusões e aquisições que impulsiona o processo de oligopolização e forma os "gigantes da educação" toma exatamente esses índices que são sistematicamente estampados na imprensa em geral e relatórios divulgados pelas empresas de consultoria, como forma de aquecer ainda mais o mercado de transações nacionais e internacionais do setor na bolsa de valores. Os resultados do IGC divulgados em 2014 indicam que $50,88 \%$ das IES públicas tiveram conceito 3 e $33,1 \%$ conceitos 4 ou 5 , enquanto que nas privadas $68,96 \%$ ficaram com conceito 3 e somente $14,31 \%$ tiveram conceitos 4 ou 5 (Ministério da Educação, 2015a). Quanto ao IGC das IES ligadas aos sete grupos investigados (Tabela 3) que possuem cursos de Psicologia, consta que em sua maioria são instituições com conceito 3 $(65,11 \%)$, seguido do conceito $4(16,27 \%)$. Somente uma IES obteve conceito 5 .

O ENADE enquanto exame obrigatório é utilizado para avaliar o rendimento dos alunos dos cursos de graduação, considerando os conteúdos programáticos, 
habilidades e competências adquiridas em sua formação, tendo periodicidade trienal para cada área do conhecimento. Na avaliação de 2012, a última que até então o INEP tinha divulgado o resultado da avaliação dos estudantes de Psicologia, 56,5\% dos cursos participantes ficaram com conceito 3 e $22 \%$ com conceito 4 , enquanto 13,2\% atingiu o conceito 2, com rendimento baixo. Ademais, das 14 IES que atingiram conceito 5 , nove eram públicas e cinco privadas. No caso das IES que obtiveram conceito 3 , $39,1 \%$ eram públicas e $64,4 \%$ privadas; e com conceito 4 , $30,4 \%$ eram públicas e $20,13 \%$ privadas (Brasil, 2014). Se tomarmos os cursos de Psicologia que integram as IES dos grupos nacionais investigados neste estudo, observa-se que $50 \%$ atingiram nota 3 , e uma quantidade considerável não conta com nenhum conceito (39\%).

Considerando a atratividade que a Psicologia representa, por ser um curso que exige baixos custos de implantação, mas também pela forte cultura psicológica já enraizada na sociedade brasileira que a vê como capaz de resolver problemas de ajustamento de comportamento e/ou de personalidade, ou por favorecer autoconhecimento e autoaprimoramento pessoal e profissional; somado ainda a condição de estar entre os 10 cursos com maior número de matrículas e inscrições em processos seletivos nacionais; e por estar hegemonicamente localizada no setor privado, isso coloca as graduações em Psicologia, ao lado de outros cursos que também são bastante consumidos no mercado do ensino superior, com potencial de interesse para que grandes grupos adquiram novas IES no mercado de fusões e oligopolização e financeirização do setor.

Contudo, alguns impasses têm sido levantados nesse processo, especialmente para estudantes e professores, no desempenho de sua atividade-fim que são os processos formativos. Santos et al. (2013) alertam para o perigo da interferência das relações mercantis com a flexibilização não apenas da estrutura de gestão e administrativa das IES, mas dos próprios processos acadêmicos e pedagógicos fundamentalmente caracterizados com base conteudista e associado a práticas instrumentais e tecnicistas para atender as necessidades do mercado. A reestruturação com corte de gastos com pessoal, redução do número de professores, a padronização dos cursos e dos currículos, a oferta de disciplinas presenciais com $20 \%$ da carga horária não presencial, a fusão de turmas, a padronização dos currículos e a flexibilização com retirada dos pré-requisitos das disciplinas, são algumas medidas que têm sido adotadas pelas IES dos grandes grupos para a obtenção de ganhos em escala.
A tendência de elaborar produtos ou concepções educativas para serem comercializados ou franqueados entre as IES de um mesmo grupo, como por exemplo: "planos de ensino, currículos, programas e, até mesmo, a forma como as aulas serão ministradas" (Santos et al., 2013, p. 88), já é uma realidade em muitas localidades. Assim, segue-se maximizando a produção de mais-valia com a manutenção e o aprofundamento da sobrecarga, da intensificação e da precarização das condições de trabalho, estratégias de flexibilização que alimentam o rentável mercado financeiro. Essa lógica, porém, não é exclusiva dos grandes players. IES menores ou mesmo grupos menores também têm adotado medidas semeIhantes para diminuir custos e maximizar lucros.

\section{Considerações finais}

Discorremos ao longo desse artigo sobre o processo de crescimento e expansão do ensino superior no Brasil, com ênfase para hegemonia no setor privado. Esse quadro marcou a formação superior no país sob duas grandes características. A primeira foi em relação a interiorização do ensino superior, em grande medida reflexo das políticas educacionais implementadas nos Governos Lula-Dilma, que abriu novas possibilidades de ampliação do acesso, inclusive em localidades/regiões mais longínquas dos grandes centros urbanos, com maior peso no setor privado. A segunda tem a ver com o caráter sempre muito funcional do Estado brasileiro ao capitalismo monopolista, que acarretou, no caso da educação superior, novos contornos com a tendência a oligopolização e a financeirização do setor, por meio do mercado de fusões e aquisições de IES por grandes empresas ou grupos educacionais nacionais e internacionais. Tendência também observada em outros países das Américas, a exemplo do Chile e do México, cujos riscos precisam ser melhor dimensionados (Serafim, 2011).

A Psicologia figura há anos entre os 10 cursos mais procurados e com maior número de matrículas. Além disso, chama atenção o significativo percentual de cursos ofertados por grandes grupos educacionais no Brasil, inclusive com a participação de grupos transnacionais. Os resultados apresentados reafirmam a preocupação de Bastos et al. (2011) diante dos impasses colocados a formação em Psicologia há alguns anos, notadamente relacionados a qualidade dos processos formativos em jogo no setor privado. Podemos, a partir das reflexões aludidas, destacar que essa preocupação é extensiva tanto para os cursos ofertados pelas IES dos grandes players 
da educação brasileira, quanto em instituições menores, em que os valores do mercado reestruturam não apenas os aspectos organizativos e gerenciais das instituições, mas também interferem nos processos acadêmicos e formativos ao se aproximarem ou adotarem concepções e estruturas de ensino que se revelam pouco satisfatórias ao processo de formação superior.

\section{Referências}

Alves, G. (2009). Trabalho e reestruturação produtiva no Brasil neoliberal: precarização do trabalho e redundância salarial. Revista Katálysis, 12(2), 188-197. doi: 10.1590/S1414-49802009000200008

Antunes, R. (1999). Os sentidos do trabalho. São Paulo: Boitempo Editorial.

Bastos, A. V. B., \& Gomide, P. I. C. (1989). O psicólogo brasileiro: sua atuação e formação profissional. Psicologia, Ciência e Profissão, 9(1), 6-15. doi: 10.1590/S1414-98931989000100003

Bastos, A. V. B., Gondim, S. M. G., \& Rodrigues, A. C. A. (2010). Uma categoria profissional em expansão: quantos somos e onde estamos? In A. V. B. Bastos \& S. M. G. Gondim (Orgs.), O trabalho do psicólogo no Brasil (pp. 32-44). Porto Alegre: Artmed.

Bastos, A. V. B., Gondim, S. M. G., Souza, J. A. J., \& Souza, M. P. R. (2011). Formação básica e profissional do psicólogo: uma análise do desempenho das IES no ENADE2006. Avaliação Psicológica, 10(3), 313-347. Recuperado de http://pepsic.bvsalud.org/scielo.php?script=sci_arttext\&pi$\mathrm{d}=$ S1677-04712011000300006\&lng=pt\&tIng=pt

Bittencourt, H. R., Casartelli, A. O., \& Rodrigues, A. C. M. (2009). Sobre o índice geral de cursos (IGC). Avaliação: Revista da Avaliação da Educação Superior, 14(3), 667-682. doi: 10.1590/ S1414-40772009000300008

Carvalho, C. H. A. (2013). A mercantilização da educação superior brasileira e as estratégias de mercado das instituições lucrativas. Revista Brasileira de Educação, 18(54), 761-776. doi: 10.1590/ S1413-24782013000300013

Chaves, V. L. J (2010). Expansão da privatização/mercantilização do ensino superior brasileiro: a formação dos oligopólios. Educação \& Sociedade, 31(111), 481-500. doi: 10.1590/ S0101-73302010000200010

Corbucci, P. R. (2004). Financiamento e democratização do acesso à educação superior no Brasil: da deserção do Estado ao projeto de reforma. Educação \& Sociedade, 25(88), 677-701. doi: 10.1590/ S0101-73302004000300003

Elias, D. S. (2007). Agricultura e produção de espaços urbanos não metropolitanos: notas teórico-metodológicas. In M. E. B. Sposito (Org.), Cidades médias: espaços em transição (pp. 113-138). São Paulo: Expressão Popular.

Gaspar, R., \& Fernandes, T. (2014). Mercantilização e oligopolização no ensino superior privado. Educação \& Realidade, 39(3), 945-966. Recuperado de http://www.scielo.br/pdf/edreal/v39n3/v39n3a17.pdf

Gomide, P. I. C. (1988). A formação acadêmica: onde residem suas deficiências? In Conselho Federal de Psicologia (Org.), Quem é o psicólogo brasileiro? (pp. 69-85). São Paulo: Edicon

Instituto Brasileiro de Geografia e Estatística. (2015). Síntese de indicadores sociais: uma análise das condições de vida da população brasileira: 2015. Rio de Janeiro: IBGE.
Landini, F. P. (2015). Problemas enfrentados por extensionistas rurais brasileiros e sua relação com suas concepções de extensão rural Ciência Rural, 45(2), 371-377. doi: 10.1590/0103-8478cr20140598

Macedo, J. P., \& Dimenstein, M. (2011). Expansão e interiorização da psicologia: reorganização dos saberes e poderes na atualidade. Psicologia: Ciência e Profissão, 31(2), 296-313. doi: 10.1590/ S1414-98932011000200008

Mancebo, D. (2015). Educação superior no Brasil: expansão e tendências (1995- 2014). In Associação Nacional de Pós-graduação e Pesquisa em Educação (Org.), Anais da $37^{a}$ Reunião Anual da ANPEd. (vol. 37. pp. 1-18). Florianópolis, SC: Autor.

Marques, R. M., \& Mendes, A. (2007). Servindo a dois senhores: as políticas sociais no governo Lula. Revista Katálysis, 10(1), 15-23. doi: 10.1590/S1414-49802007000100003

Martins, C. B. (2009). A reforma universitária de 1968 e a abertura para o ensino superior privado no Brasil. Educação \& Sociedade, 30(106), 15-35. doi: 10.1590/S0101-73302009000100002

Mello, M. A. A. V., \& Callou, A. B. F. (2010). Tecnologia social, extensão rural e desenvolvimento local: o gerenciamento integrado de resíduos sólidos em Pernambuco. Contexto \& Educação, 25(83), 153-175. doi: 10.21527/2179-1309.2010.83.153-175

Ministério da Educação (1995). Instituto Nacional de Estudos e Pesquisas Educacionais (INEP). Micro dados do Censo da Educação Superior 1995. Resumo técnico. Brasília, DF: MEC; INEP

Ministério da Educação (2002). Instituto Nacional de Estudos e Pesquisas Educacionais (INEP). Censo da Educação Superior 2002. Resumo técnico. Brasília, DF: MEC; INEP.

Ministério da Educação (2014). Instituto Nacional de Estudos e Pesquisas Educacionais (INEP). Censo da Educação Superior 2012. Resumo técnico. Brasília, DF: MEC; INEP.

Ministério da Educação (2015a). Instituto Nacional de Estudos e Pesquisas Educacionais (INEP). Censo da Educação Superior 2014. Notas estatísticas. Brasília, DF: MEC; INEP.

Ministério da Educação (2015b). Instituto Nacional de Estudos e Pesquisas Educacionais (INEP). Censo da Educação Superior 2013. Resumo técnico. Brasília, DF: MEC; INEP.

Netto, J. P. (2004). Notas sobre a reestruturação do Estado e a emergência de novas formas de participação da sociedade civil. In I. Bochetti (Org.), Política Social: alternativas ao neoliberalismo. (pp. 61-83). Brasília, DF: UNB.

Oliveira, R. F. (2011). A contra-reforma do Estado no Brasil: uma análise crítica. Revista Urutágua -Aacadêmica Multidisciplinar, 24, 132-146. Recuperado de http://periodicos.uem.br/ojs/index.php/ Urutagua/article/view/10698

Rocha, F. E. C., Albuquerque, F. J. B., \& Marcelino, M. Q. S. (2008) Avaliação de programa: aspectos teóricos e metodológicos no contexto da agricultura familiar. Documentos. Embrapa Cerrados, 211, 1-62. Recuperado de http://www.infoteca.cnptia.embrapa.br/ infoteca/handle/doc/571909

Rothen, J. C., \& Barreyro, G. B. (2011). Avaliação da educação superior no segundo governo Lula: provão II ou a reedição de velhas práticas?. Educação \& Sociedade, 32(114), 21-38. doi: 10.1590/ S0101-73302011000100002

Sampaio, H. (1991). Evolução do ensino superior brasileiro, 1808-1990. Documento de trabalho 8/91, NUPES/USP. Recuperado de http:// nupps.usp.br/downloads/docs/dt9108.pdf

Santos, A. V., Guimarães-losif, R. M., \& Chaves, V. L. (2013). Formação dos oligopólios na educação superior privada brasileira: 
sobreimplicação no trabalho docente. Revista Educação em Questão, 46(32), 75-97. Recuperado de https://periodicos.ufrn.br/ educacaoemquestao/article/view/5123

Serafim, M. P. (2011). O processo de mercantilização das instituições de educação superior: um panorama do debate nos EUA, Europa e na América Latina. Avaliação, 16(2), 241-265. doi: 10.1590/ S1414-40772011000200002

Sguissardi, V. (2000). Educação superior: o banco mundial reformará suas teses e o Brasil reformará sua política? Revista Educação Brasileira, 22(45), 11-53.

Silva Jr., A., Polizel, C. E. G., Souza, S., Silva, A. R. L., Silva, P. O. M., \& Souza, S. P. (2014). Políticas públicas para a educação superior: a avaliação, a regulação e a supervisão de IES privadas em debate.
Ensaio: Avaliação e Políticas Públicas em Educação, 22(82), 215240. doi: 10.1590/S0104-40362014000100011

Tavares, P. H.S. (2014). Os fundos de investimentos e o movimento do capital no ensino superior privado: mercantilização de novo tipo? (Dissertação de Mestrado não publicada). Universidade Federal do Rio de Janeiro, Rio de Janeiro.

Verhine, R. E., \& Dantas, L. M. V. (2009). A avaliação do desempenho de alunos de educação superior: uma análise a partir da experiência do ENADE. In J. A. C. Lordêlo \& M. V. Dazzani (Orgs.), Avaliação educacional: desatando e reatando nós (pp. 174-199). Salvador: EDUFBA.

Yamamoto O. H., Falcão, J. T. R., \& Seixas, P. S. (2011). Quem é o estudante de psicologia do Brasil?. Avaliação Psicológica, 10(3), 209-232. Recuperado de http://pepsic.bvsalud.org/pdf/avp/v10n3/v10n3a02.pdf

1. Bastos e Gomide (1989) já alertavam para a hegemonia das IES privadas na oferta de cursos de graduação em Psicologia na década de 1980, com o domínio de $70 \%$ do setor.

Joao Paulo Macedo, Doutor em Psicologia pela Universidade Federal do Rio Grande do Norte (UFRN), é Docente do Programa de PósGraduação em Psicologia da Universidade Federal do Piauí (UFPI). Endereço para correspondência: Universidade Federal do Piauí, Campus Ministro Reis Velloso. Av. São Sebastião, 2819 - São Benedito, Parnaíba - PI, CEP: 64202-020. E-mail: jpmacedo@ufpi.edu.br

Brenda Brito Ramos, é Graduanda em Psicologia e Bolsista PIBIC pela Universidade Federal do Piauí (UFPI).

E-mail: brenda2010ifma@hotmail.com

Carlivane de Jesus Souza, é Graduanda em Psicologia e Bolsista PIBIC pela Universidade Federal do Piauí (UFPI).

E-mail: carlivane.sj@hotmail.com

Marta Savana de Sousa Lima, é Graduanda em Psicologia e Bolsista PIBIC pela Universidade Federal do Piauí (UFPI).

E-mail: marthasavana@gmail.com

Karyne Pamela B.C Fonseca, é Graduanda em Psicologia e Bolsista PIBIC pela Universidade Federal do Piauí (UFPI). E-mail: karyne.barross@hotmail.com

Recebido em 06.Set.17 Revisado em 17.Dez.17 Aceito em 20.Abr.18 